Available online:

IMLA http://journal.imla.or.id/index.php/arabi

Arabi : Journal of Arabic Studies, 1 (2), 2016, 34-49

\title{
RANCANG BANGUN APLIKASI IKHTIBAR TASHNIFI BERBASIS WEB UNTUK MAHASISWA BARU JURUSAN SASTRA ARAB
}

\author{
Mohammad Ahsanuddin \\ Universitas Negeri Malang \\ E-mail: mohammad.ahsanuddin.fs@um.ac.id
}

\begin{abstract}
In every academic year, the department of Arabic literature, Malang State University arranges ikhtibar tashnifi (placement test) for new students aimed to know their competence in Arabic language. Previously, the test was held through paper-pencil test. This research was aimed to develop steps in designing ikhtibar tashnifi web-based application for placement test and describe the use of web-based placement test. The method used was R\&D (Research \& Development). Some steps were conducted: preliminary study, product development, professional testing, revision, limited experiment, revision, and final product. The respondents were all the new students of Arabic literature department at the university academic year 2013. The research found the major concern in designing this application was observing, doing library research, and designing the program. Before it is used, the program should be first installed in the local server, creating database, and running the program. The validity of ikhtibar is $81,25 \%$, while the result of media professional analysis is $85 \%$.
\end{abstract}

Keywords: Ikhtibar Tashnifi (placement test), web, Arabic language

\section{Abstrak}

Setiap tahun akademik baru, Jurusan Sastra Arab Fakultas Sastra Universitas Negeri Malang (UNM) mengadakan ikhtibar tashnifi (tes penempatan) untuk mahasiswa baru yang bertujuan untuk mengetahui kemampuan awal mereka dalam penguasaan terhadap bahasa Arab. Pelaksanaan tes penempatan dilaksanakan secara manual. Tujuan penelitian ini adalah untuk (1) mengembangkan langkah-langkah desain aplikasi ikhtibar tashnifi berbasis web, (2) mendeskripsikan penggunaan aplikasi ikhtibar tashnifi (tespenempatan) berbasis web. Metode penelitian yang digunakan adalah metode $R \& D$. Tahapan penelitian ini yakni: studi pendahuluan, pengembangan produk, uji ahli, revisi, uji coba terbatas, revisi, dan produk akhir. Subjek dalam penelitian ini adalah semua mahasiswa baru jurusan Sastra Arab Fakultas Sastra UNM angkatan 2013. Hasil penelitian tersebut adalah: Hal yang perlu di perhatikan adalah observasi, mengkaji bahan pustaka, dan mendesain program ikhtibar. Sebelum digunakan, program terlebih dahulu harus diinstal server lokal, membuat database dan menjalankan program. Kevalidan materi ikhtibar adalah 81,25\%, sedangkan hasil analisis dari ahli media didapatkan nilai adalah $85 \%$.

Kata Kunci: ikhtibar tashnifi (tes penempatan), web, bahasa Arab 


\section{Pendahuluan}

Jurusan Sastra Arab Fakultas Sastra Universitas Negeri Malang memiliki satu program studi (prodi) yaitu Pendidikan Bahasa Arab (PBA). Untuk dapat menjadi mahasiswa prodi PBA, pada tahun akademik 2013/2014 ini calon mahasiswa mengikuti beberapa sistem penerimaan mahasiswa baru, yaitu: Seleksi Nasional Masuk Perguruan Tinggi Negeri (SNMPTN), Seleksi Bersama Masuk Perguruan Tinggi Negeri (SBMPTN), dan Seleksi Mandiri. Input mahasiswa baru di Prodi PBA beragam ada yang dari Sekolah Menengah Atas (SMA)/sederajat dan Madrasah Aliyah (MA)/sederajat.

Untuk kemampuan awal mahasiswa baru terhadap penguasaan bahasa Arab, prodi PBA mengadakan ikhtibar tashnifi (tes penempatan). Tes penempatan dalam proses pembelajaran digunakan untuk mengetahui kondisi obyektif dari peserta didik, sehingga memudahkan pengajar untuk menentukan posisi peserta didik dengan materi yang sesuai dengan kemampuan masingmasing peserta didik.

Menurut Djiwandono (2011: 86) bahwa penyelenggaraan tes penempatan dimaksudkan untuk menempatkan peserta tes yang telah dinyatakan lulus pada kelompok yang sesuai berdasarkan tingkat kemampuan akademiknya. Diasumsikan terdapat lulusan tes dalam jumlah yang terlalu besar untuk disatukan dalam satu kelompok. Untuk itu perlu dibentuk kelompokkelompok yang lebih kecil, misalnya terdiri atas 20 atau 25 orang yang memiliki kesamaan atau kemiripan menurut salah satu kriteria.

Selama ini, proses pelaksanaan ikhtibār tashnïfi pada Prodi PBA dilakukan secara manual. Dalam penyajian soal maupun untuk menuliskan jawabannya masih menggunakan media kertas (paper-based). Hal ini menyebabkan banyaknya waktu terbuang untuk mengevaluasi dan menghitung hasil tes, terjadinya kesalahan dalam proses evaluasi karena kesalahan manusia (human-error), serta memungkinkan juga terjadinya banyak kesalahan saat penyimpanan dan pendokumentasian data. Setelah pelaksanaan tes selesai, prodi PBA menunjuk tim koreksi untuk mengoreksi jawaban mahasiswa dan hasilnya diserahkan kepada ketua jurusan untuk diputuskan klasifikasi kelas berdasarkan nilai yang didapat.

Salah satu solusi untuk meminimalisir terjadinya kesalahan tersebut adalah dengan merancang suatu perangkat lunak untuk pelaksanaan ikhtibar tashnifi (tes penempatan) secara komputerisasi. Seiring dengan perkembangan teknologi yang semakin canggih, banyak perangkat lunak yang digunakan untuk pembuatan tes, di antaranya claroline, moodle, TCExam, dan ada pula yang berbasis web. Potensi untuk mengembangkan tes yang manual menjadi digital semakin besar dengan berkembangnya teknologi web. Oleh karena itu, perlu dibuatnya tes berbasis web ( $W e b$ Based Test) yang mampu menyajikan soal, menyimpan jawaban, mengevaluasi soal, dan menghitung hasilnya yang nantinyaakan menentukan level mahasiswa untuk memulai belajar Bahasa Arab di Jurusan Sastra Arab FS UM.

Rancang bangun aplikasi ikhtibar tashnifi ini berbasis web dikarenakan mempunyai kelebihan, di antaranya (1) web dioperasikan melalui browser yang memungkinkan untuk dijalankan secara online maupun offline, (2) aplikasi berbasis web lebih dinamis, dan interaktif, (3) bersifat catch on the fly yang tidak dimiliki oleh perangkat lunak lainnya.

Dalam makalah ini, penulis hanya mengembangkan butir-butir tes objektif saja yaitu pilihan ganda dan benar salah karena memiliki kelebihan, yaitu: (1) mudah dikontruksi, (2) perangkat soal dapat mewakili seluruh pokok bahasan, (3) pemberian nilai dan cara menilai test objektif lebih cepat dan mudah karena tidak menuntut keahlian khusus dari pada si pemberi nilai, (4) alat yang baik untuk mengukur fakta dan hasil belajar langsung terutama berkenaan dengan ingatan, (5) untuk menjawab test objektif tidak banyak memakai waktu, (6) reabilitasnya lebih tinggi kalau di bandingkan dengan test Essay, karena penilainnya bersifat objektif, (7) objektif test tidak memperdulikan penguasaan bahasa, sehingga mudah dilaksanakan, (8) validitas test objektif lebih tinggi dari essay test, karena samplingnya lebih luas (Hafid, 2013). Sementara itu, al-Jabal (2009: 203) menambahkan salah satu kelebihan tes objekif disamping yang disebutkan sebelumnya yaitu 


\section{Arabi : Journal of Arabic Studies}

tes objektif bisa menggunakan komputer sebagai media tes untuk kemudahan pelaksanaan dan mempercepat koreksi.

Penelitian terdahulu yang relevan dengan penelitian ini adalah penelitian Palelleng (2007) dengan judul pengembangan sistem test penempatan (placement test) berbasis komputer. Hasilnya adalah sebuah sistem yang siap diimplementasikan di LIA Yogyakarta untuk pelaksanaan test penempatan berbasis komputer. Sistem ini dapat memberi keuntungan bagi penggunanya baik dari segi kemudahan penggunaan sistem, kualitas informasi dan manfaat informasi yang dihasilkan sistem.

Penelitian Ahsanuddin dkk (2010) "Pengembangan Perangkat Lunak Berbasis Hot Potatoes Sebagai Model Tes Interaktif dalam Matakuliah Qiro'ah I (Membaca) Mahasiswa Jurusan Sastra Arab Fakultas Sastra Universitas Negeri Malang", berkesimpulan bahwa perangkat lunak berbasis hot potatoes ini berupa sebuah program evaluasi yang menyajikan materi pembelajaran qiro'ah I, kumpulan soal-soal yang dapat digunakan oleh mahasiswa untuk belajar dan mengevaluasi hasil belajar secara mandiri.

Perbedaan penelitian terdahulu dengan penelitian ini adalah program yang digunakan. Program yang digunakan pada penelitian terdahulu adalah berbasis komputer dan program claroline, sedangkan penelitian ini berbasis web.

Tujuan penulisan makalah ini adalah (a) mendeskripsikan langkah-langkah desain aplikasi ikhtibär tashnifi (tes penempatan) berbasis web untuk mahasiswa Jurusan Sastra Arab Fakultas Sastra Universitas Negeri Malang dan (b) mendeskripsikan penggunaan aplikasi ikhtibär tashnífi (tes penempatan) berbasis web untuk mahasiswa Jurusan Sastra Arab Fakultas Sastra Universitas Negeri Malang.

\section{Metode Penelitian}

Penelitian ini termasuk jenis penelitian dan pengembangan (research and develpoment; $R \& D$ ) (Sugiyono, 2008) karena bertujuan untuk menghasilkan produk. Metode R\&D dimodifikasi dengan alasan biaya, waktu dan tenaga yang terbatas. Adapun subjek dalam penelitian ini adalah mahasiswa baru jurusan Sastra Arab angkatan 2013 yang berjumlah 90 mahasiswa. Berikut langkah-langkah penelitian yang dilakukan:

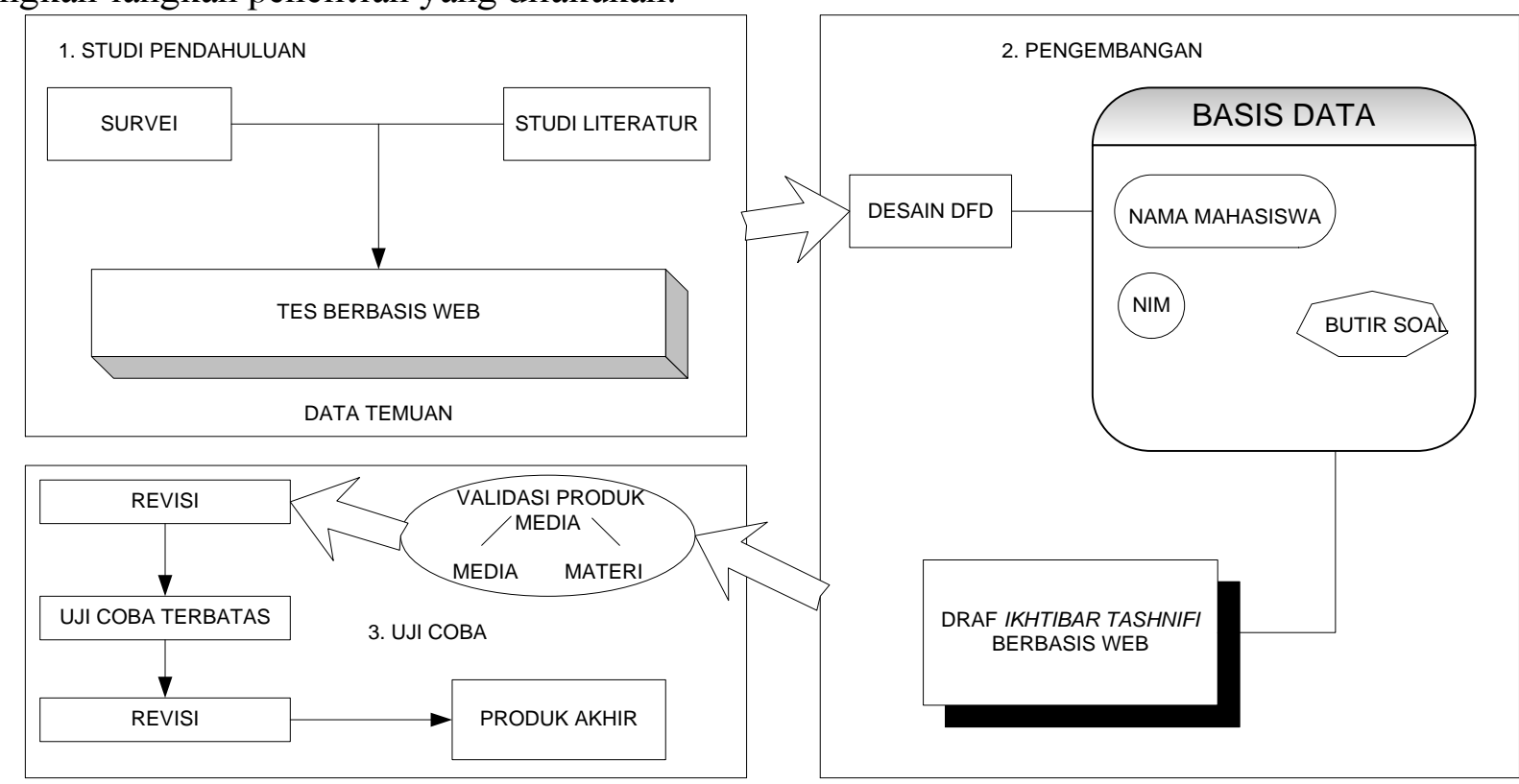

\section{Desain Penelitian}

Gambar 1: Bagan Alir Penelitian

Seperti dalam Gambar 1, penelitian ini dirancang untuk diselesaikan dalam kurun waktu enam bulan. Penelitian ini dibagi dalam beberapa tahap, yakni: studi pendahuluan, pengembangan produk, uji ahli, revisi, uji coba terbatas, revisi, dan produk akhir. 


\section{a. Studi Pendahuluan}

Studi pendahuluan merupakan kegiatan pertama peneliti dengan mengadakan observasi untuk mendapatkan data. Berdasarkan hasil observasi analisis kebutuhan dilakukan peneliti, bahwa pelaksanaan tes secara digital lebih baik dari pada tes manual, karena mudah memeriksanya dan hasilnya langsung diketahui. Oleh karena itu, peneliti memutuskan untuk mengembangkan ikhtibar tashnifi berbasis web.

\section{b. Pengembangan Produk}

Materi yang akan dikembangkan dalam penelitian ini adalah butir soal ikhtibar tashnifi berbentuk tes objektif yang disusun oleh tim dosen dan dipakai mahasiswa untuk menentukan kelas mereka dalam proses belajar mengajar. Butir soal tersebut dikembangkan dengan media elektronik berbasis web.

\section{c. Validasi Produk Media}

Uji validitas merupakan suatu langkah pengujian yang dilakukan terhadap isi (content) dari suatu instumen, dengan tujuan untuk mengukur ketepatan instrumen yang digunakan dalam suatu penelitian. Dalam pengembangan model pengajaran berbasis multimedia, maka uji validitas dimaksudkan untuk menguji sejauh mana model media yang dikembangkan dapat digunakan sebagai salah satu model, sehingga dapat diketahui tingkat kebenaran dan ketepatan penggunaan media tersebut. Uji ahli ini terbagi menjadi dua yaitu uji ahli media dan uji ahli materi.

\section{d. Revisi}

Revisi dilakukan untuk menyempurnakan aplikasi ikhtibar tashnifi berbasis web apabila produk belum memenuhi kriteria yang diharapkan setelah melakukan uji coba.

e. uji coba terbatas

Uji coba produk dimaksudkan untuk mengumpulkan data yang dapat dijadikan dasar sebagai pertimbangan dalam menetapkan keefektifan dan keefisianan suatu produk media yang dihasilkan.

\section{f. Revisi}

Revisi dilakukan untuk menyempurnakan aplikasi ikhtibar tashnifi berbasis web apabila produk belum memenuhi kriteria yang diharapkan setelah melakukan uji coba.

\section{g. Produk akhir}

Langkah terakhir adalah produk ahir dari materi yang dikembangkan.

\section{Hasil dan Pembahasan}

\section{Langkah-Langkah Desain Aplikasi Ikhtibar Tashnifi (Tes Penempatan) Berbasis Web Untuk Mahasiswa Jurusan Sastra Arab Fakultas Sastra Universitas Negeri Malang}

Mengacu kepada rancangan penelitian pengembangan, langkah pertama yang peneliti lakukan adalah studi pendahuluan yang meliputi observasi dan melakukan kajian pustaka. Sejak tahun 2011, peneliti menjadi salah satu tim pelaksanaan ikhtibār tashnifi untuk mahasiswa baru. Selama ini, proses pelaksanaannya masih bersifat manual. Dalam penyajian soal maupun untuk menuliskan jawabannya masih menggunakan media kertas (paper-based). Hal ini menyebabkan banyaknya waktu terbuang untuk mengevaluasi dan menghitung hasil tes, terjadinya kesalahan dalam proses evaluasi karena kesalahan manusia (human-error), serta memungkinkan juga terjadinya banyak kesalahan saat penyimpanan dan pendokumentasian data.

Selain mengobservasi kegiatan ikhtibär tashnïfi tersebut, peneliti juga melakukan kajian pustaka dengan membaca beberapa hasil penelitian tentang tes berbasis komputer. Salah satu hasil penelitian yang peneliti kaji adalah penelitian yang berjudul pengembangan sistem test penempatan (placement test) berbasis komputer yang dilakukan oleh Palelleng (2007). Hasil penelitiannya adalah sebuah sistem yang siap diimplementasikan di LIA Yogyakarta untuk pelaksanaan test penempatan berbasis komputer. Sistem ini dapat memberi keuntungan bagi penggunanya baik dari segi kemudahan penggunaan sistem, kualitas informasi dan manfaat 


\section{Arabi : Journal of Arabic Studies}

informasi yang dihasilkan sistem. Dari hasil observasi dan kajian pustaka tersebut, akhirnya peneliti mengembangkan ikhtibär tashniffi berbasis web.

Langkah kedua adalah pengembangan produk ikhtibär tashnifi. Sebelum ikhtibär tashnifi digunakan langkah pertama yang dilakukan adalah menginstal server lokal (localhost server) yang meliputi install wamp server atau xampp, membuat data base dan menjalankan program ikhtibär tasnhïfi. Langkah kedua yaitu memasukkan butir-butir soal ke dalam program kemudian diupload ke internet.

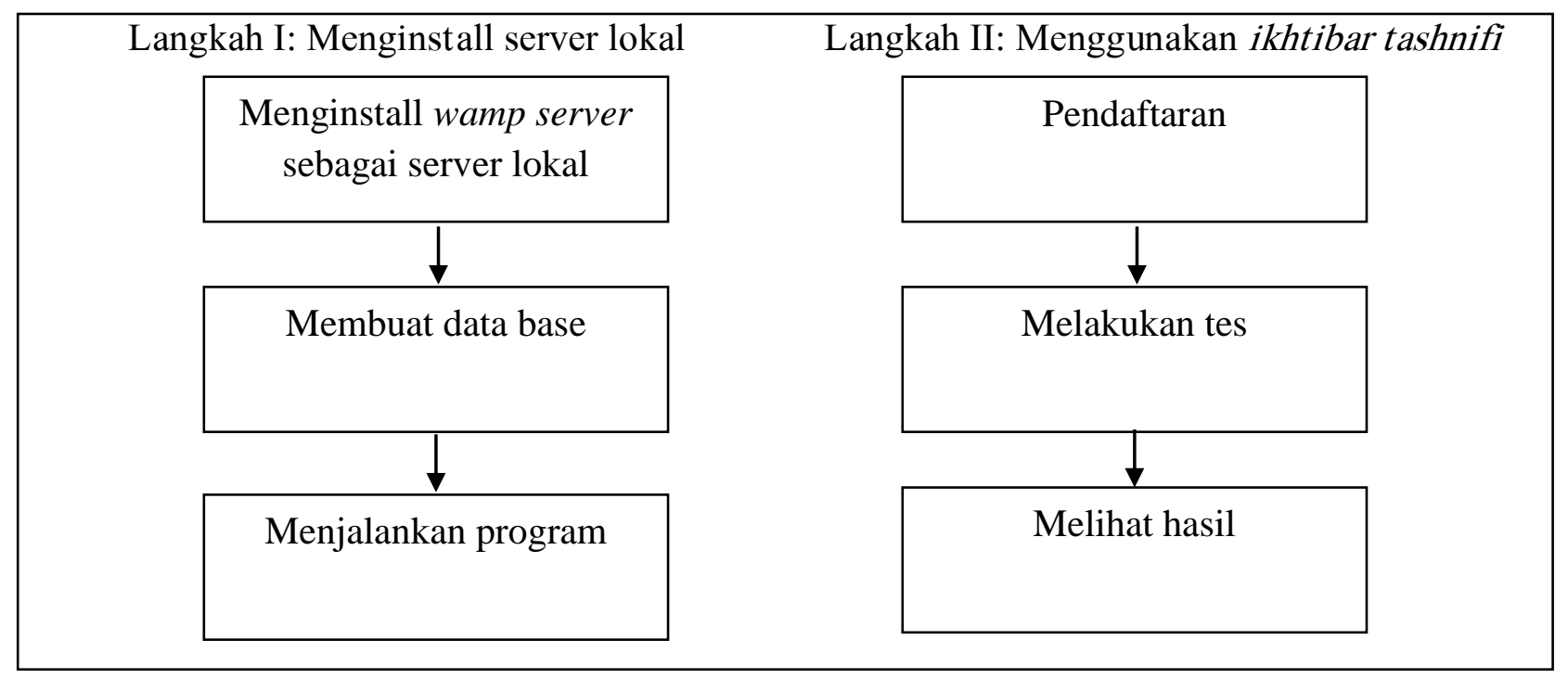

\section{c. Membuat Ikhtibār Tashniffi}

Setelah database dibuat, langkah selanjutnya adalah menjalankan program ikhtibar tashnifi. Berikut langkahnya:

- Buka browser dan ketik pada addresbar alamat localhost/dsn3 maka akan muncul tampilan berikut:

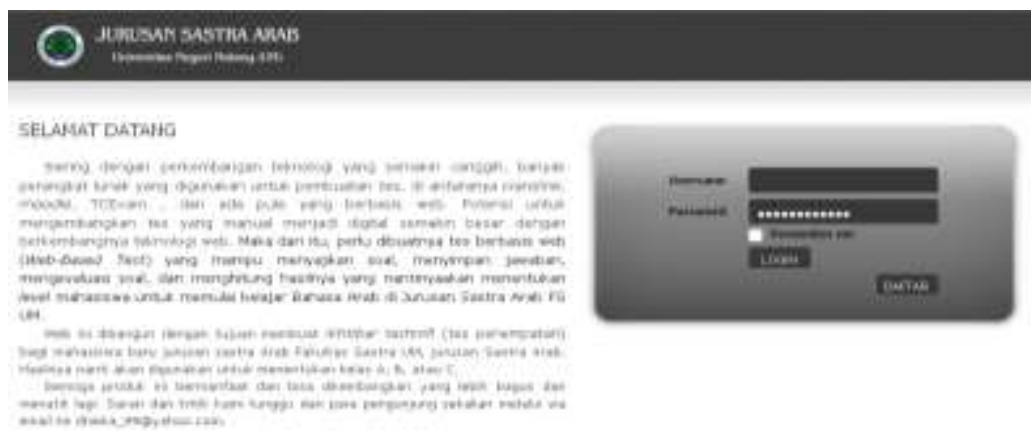

Gambar 4.10: Tampilan awal program ikhtibār tashnïfi

Pada program tersebut ada dua akses yaitu akun admin dan akun mahasiswa. Akun admin digunakan untuk mengelola program yang meliputi membuat butir soal, menentukan jawaban, menentukan kelas, dan lain-lain. Sedangkan akun mahasiswa digunakan untuk mengerjakan soal yang sudah dibuat.

Untuk bisa ke akun admin, alamat yang dituju adalah www.arab-um.com/iktibar/panel mengisi username dan password dan akan muncul tampilan seperti gambar 4.11. 

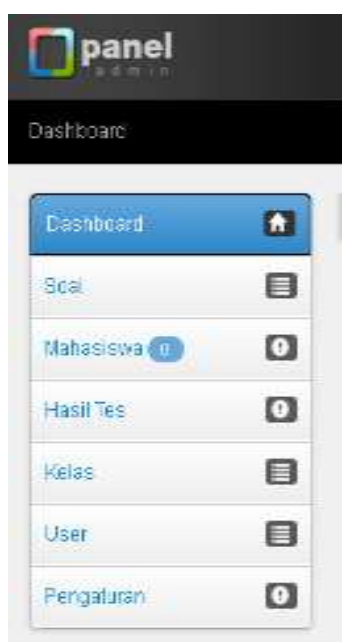

Gambar 4.11 tampilan akun admin

Pada menu admin ini berisi pengaturan soal, pengaktifan akun mahasiswa, penentian hasil kelas, menentukan jumlah kelas, user dan pengaturan secara umum. Menu pengaturan soal berisi soal yang akan dibuat meliputi soal pilihan ganda dan soal benar salah. Berikut contoh isian soal pilihan ganda dan benar salah:

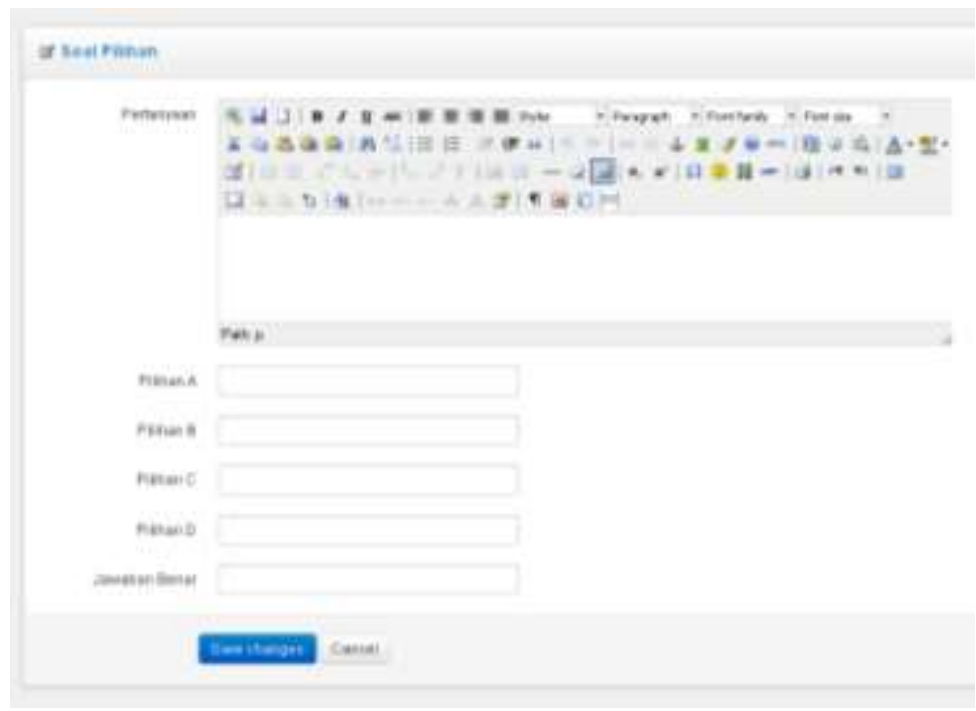

Gambar 4.12 tampilan isian soal pilihan ganda

Tampilan di atas merupakan tampilan isian soal pilihan ganda. Peneliti menulis pertanyaan pada kolom pertanyaan, misalnya:

$$
\text { الكلمات الغريبة هي، كراسة - مسطرة - ملبس - قلم. }
$$

kemudian menulis jawaban pada pilihan A, B, C, dan D. Setelah itu menentukan jawaban yang benar.

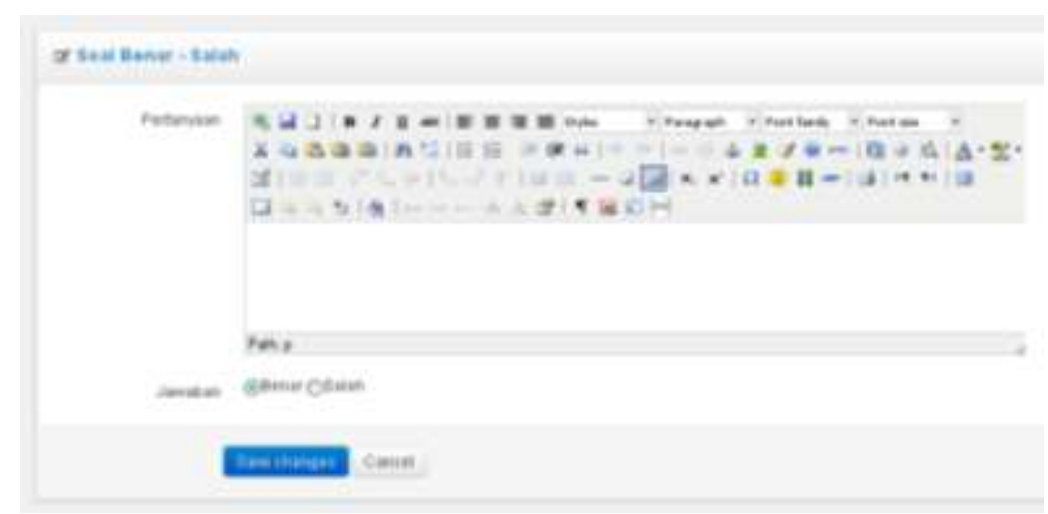

Gambar 4.13 tampilan isian soal benar salah 


\section{Arabi : Journal of Arabic Studies}

Penulisan soal benar-salah juga sama dengan soal pilihan ganda. Peneliti menuliskan soal pada kolom pernyataan kemudian menetukan jawaban benar atau salah dari pernyataan tersebut.

Setelah peneliti mendesain ikhtibär tashniffi kemudian media itu diuji validasi kepada ahli materi dan ahli media. Berikut ini diapaparkan hasil angket validasi ahli materi dan ahli media.

Berdasarkan hasil angket baik uji ahli materi maupun ahli media didapatkan data sebagai berikut:

Tabel 4.5 Uji ahli materi

\begin{tabular}{|l|l|c|l|}
\hline No & \multicolumn{1}{|c|}{ Aspek Penilaian } & Skor & \multicolumn{1}{|c|}{ Keterangan } \\
\hline 1 & $\begin{array}{l}\text { Kesesuaian soal dengan materi yang akan } \\
\text { diajarkan }\end{array}$ & 3 & $\begin{array}{l}\text { Menarik/ jelas/ baik/ } \\
\text { mudah }\end{array}$ \\
\hline 2 & Sistematika penyajian soal & 3 & $\begin{array}{l}\text { Menarik/ jelas/ baik/ } \\
\text { mudah }\end{array}$ \\
\hline 3 & $\begin{array}{l}\text { Materi yang disajikan jauh dari kesalahan } \\
\text { penulisan }\end{array}$ & 3 & $\begin{array}{l}\text { Menarik/ jelas/ baik/ } \\
\text { mudah }\end{array}$ \\
\hline 4 & Penggunaan uslüb bahasa Arab & 3 & $\begin{array}{l}\text { Menarik/ jelas/ baik/ } \\
\text { mudah }\end{array}$ \\
\hline 5 & Kevalidan soal yang dibuat & 4 & $\begin{array}{l}\text { Sangat menarik/ sangat } \\
\text { jelas/ sangat baik/ sangat } \\
\text { mudah }\end{array}$ \\
\hline 6 & Kemenarikan bentuk soal & 3 & $\begin{array}{l}\text { Menarik/ jelas/ baik/ } \\
\text { mudah }\end{array}$ \\
\hline 7 & Kesesuaian pertanyaan dengan jawaban & 4 & $\begin{array}{l}\text { Sangat menarik/ sangat } \\
\text { jelas/ sangat baik/ sangat } \\
\text { mudah }\end{array}$ \\
\hline 8 & Penulisan soal sesuai dengan kaidah & 3 & $\begin{array}{l}\text { Menarik/ jelas/ baik/ } \\
\text { mudah }\end{array}$ \\
\hline & Jumlah & 26 & V6 $\mathbf{1 0 0 = 8 1 , 2 5 \%}$ \\
\hline $\mathbf{3 2}$ & & Valid \\
\hline
\end{tabular}

Berdasarkan hasil tabel di atas, dapat diketahui bahwa kelayakan atau kevalidan dari materi ikhtibär tashnifi adalah 81,25\%. Rekomendasi yang diberikan oleh ahli materi adalah valid akan tetapi saran yang diberikan oleh validator adalah (a) pengklasifikasian butir soal akan lebih memudahkan peserta ujian apabila berdasarkan kelompok tema (Contohnya; Fahm al-Masmü', Fahm al-Maqrü', dan lain-lain), bukan berdasarkan jenis soal (pilihan ganda/benar salah) dan (b) jumlah item soal, variasi jenis soal, dan juga jumlah kelompok tema sebaiknya perlu ditambah, agar benar-benar bisa mengukur kemampuan awal peserta ujian.

Tabel 4.6: Uji ahli media

\begin{tabular}{|l|l|c|l|}
\hline No & \multicolumn{1}{|c|}{ Aspek Penilaian } & Skor & \multicolumn{1}{|c|}{ Keterangan } \\
\hline 1 & Penyajian soal objektif dengan berbasis web & 4 & $\begin{array}{l}\text { Sangat menarik/ } \\
\text { sangat jelas/ sangat } \\
\text { baik/ sangat mudah }\end{array}$ \\
\hline 2 & Kejelasan soal objektif berbasis web & 3 & $\begin{array}{l}\text { Menarik/ jelas/ } \\
\text { baik/ mudah }\end{array}$ \\
\hline 3 & Kevalidan soal objektif berbasis web & 3 & $\begin{array}{l}\text { Menarik/ jelas/ } \\
\text { baik/ mudah }\end{array}$ \\
\hline 4 & Kevariatifan soal objektif berbasis web & 3 & $\begin{array}{l}\text { Menarik/ jelas/ } \\
\text { baik/ mudah }\end{array}$ \\
\hline 5 & Kesesuaian Soal dengan Materi Pembelajaran & 3 & $\begin{array}{l}\text { Menarik/ jelas/ } \\
\text { baik/mudah }\end{array}$ \\
\hline 6 & Kemudahan Menggunakan web & 4 & Sangat menarik/ \\
\hline
\end{tabular}

Vol. 1 No. $2 \mid 40-49$

Copyright @ 2016 | ARABI | p-ISSN 2548-6616 | e-ISSN 2548-6624 
Arabi : Journal of Arabic Studies

\begin{tabular}{|l|l|c|l|}
\hline & & & $\begin{array}{l}\text { sangat jelas/ sangat } \\
\text { baik/ sangat mudah }\end{array}$ \\
\hline 7 & Kelengkapan Fitur dalam program & 3 & $\begin{array}{l}\text { Menarik/ jelas/ } \\
\text { baik/ mudah }\end{array}$ \\
\hline 8 & $\begin{array}{l}\text { Desain dan Tampilan ikhtibär tashnifi berbasis } \\
\text { web }\end{array}$ & 3 & $\begin{array}{l}\text { Menarik/ jelas/ } \\
\text { baik/ mudah }\end{array}$ \\
\hline 9 & Kejelasan materi dalam web & 4 & $\begin{array}{l}\text { Sangat menarik/ } \\
\text { sangat jelas/ sangat } \\
\text { baik/ sangat mudah }\end{array}$ \\
\hline 10 & Manfaat tes ikhtibär tashnïfi berbasis web & 4 & $\begin{array}{l}\text { Sangat menarik/ } \\
\text { sangat jelas/ sangat } \\
\text { baik/ sangat mudah }\end{array}$ \\
\hline & $\begin{array}{l}\text { Jumlah } \\
\mathbf{4 0} \mathbf{1 0 0}=\mathbf{8 5 \%}\end{array}$ & 34 & \multicolumn{1}{|c|}{ Valid } \\
\hline
\end{tabular}

Berdasarkan hasil tabel di atas, dapat diketahui bahwa kelayakan atau kevalidan dari media ikhtibār tashnifi adalah 85\%. Rekomendasi yang diberikan oleh ahli materi adalah valid dan saran yang diberikan oleh validator adalah (a) model soal berbasis on-line seperti ini sangat membantu dan mempermudah pelaksanaan dan pengoreksian hasil ujian, (b) perlu adanya proses pengembangan dan penyempurnaan yang bersifat terus-menerus, agar variasi dan juga tingkat validitas soal bisa terjaga dan ditingkatkan.

Untuk menguji kevalidan program ikhtibār tashnīfi yang telah dibuat, peneliti juga melakukan uji coba terbatas kepada mahasiswa angkatan 2010 yang berjumlah 15 orang.

2. Mendeskripsikan penggunaan aplikasi ikhtibār tashnifi (tes penempatan) berbasis web untuk mahasiswa Jurusan Sastra Arab Fakultas Sastra Universitas Negeri Malang

Sebelum mahasiswa mengerjakan semua ikhtibär tashnifi, mereka harus mendaftar terlebih dahulu dengan mengklik tombol daftar. Form yang ada harus diisi semua oleh mahasiswa kemudian klik kirim (lihat gambar 4.15). Setelah form dikirim, admin kemudian mengaktifkan akun mahasiswa dan mahasiswa melakukan login (lihat gambar 4.16).

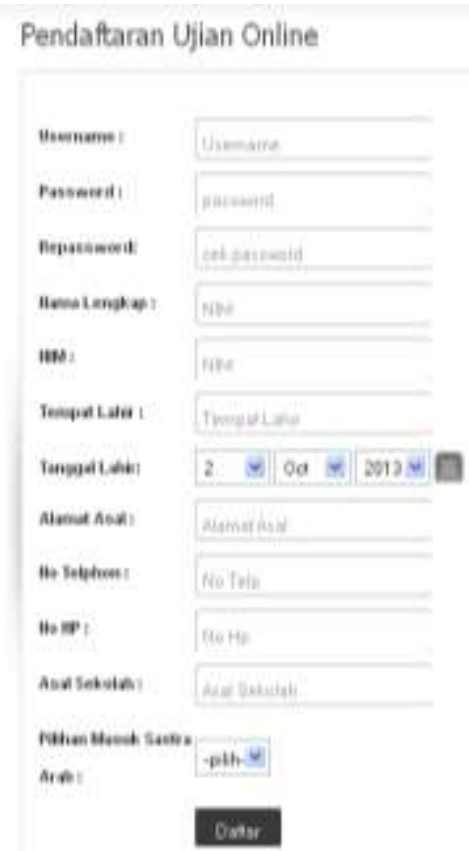

Gambar 4.14 Tampilan form isian pendaftaran 


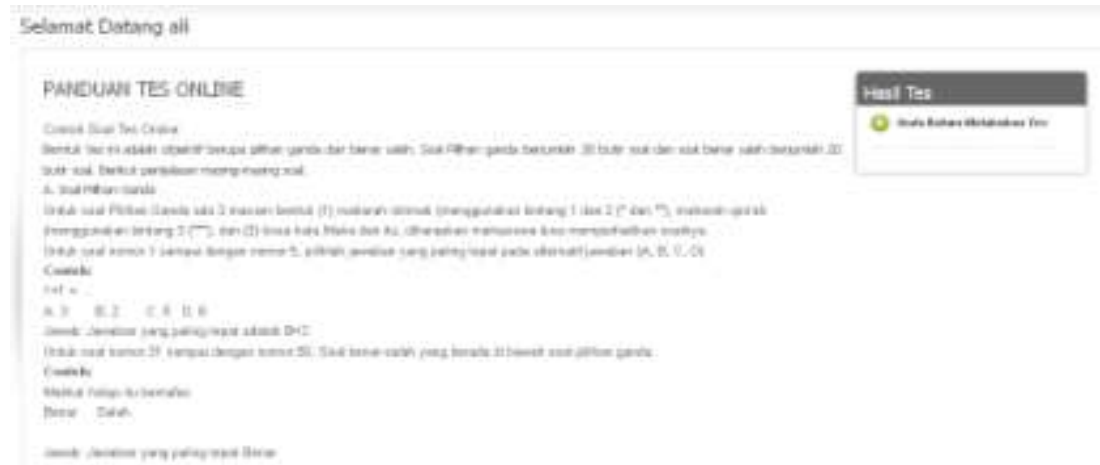

Gambar 4.15 tampilan akun mahasiswa

Pada gambar 4.15 di atas merupakan tampilan awal akun mahasiswa. Dalam akun tersebut terdapat beberapa menu yaitu dashboard, team pengembang, ujian, hasil dan link. Dashboard merupakan menu utama dari web dan berisi panduan tes online. Sedangkan team pengembang merupakan susunan pengembang ikhtibar tashnifi (lihat gambar 4.17). Menu ujian berisi butirbutir soal yang diujikan yang meliputi tes pilihan ganda (30 butir soal) dan tes benar salah (20 butir soal) (lihat gambar 4.18 dan 4.19). Adapun menu hasil merupakan akumulasi hasil pilihan ganda dan benar salah serta penentuan kelas (lihat gambar 4.20).

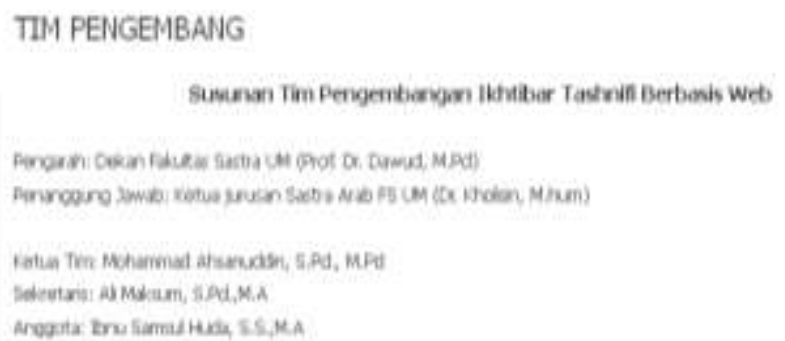

Gambar 4.16 susunan team pengembang

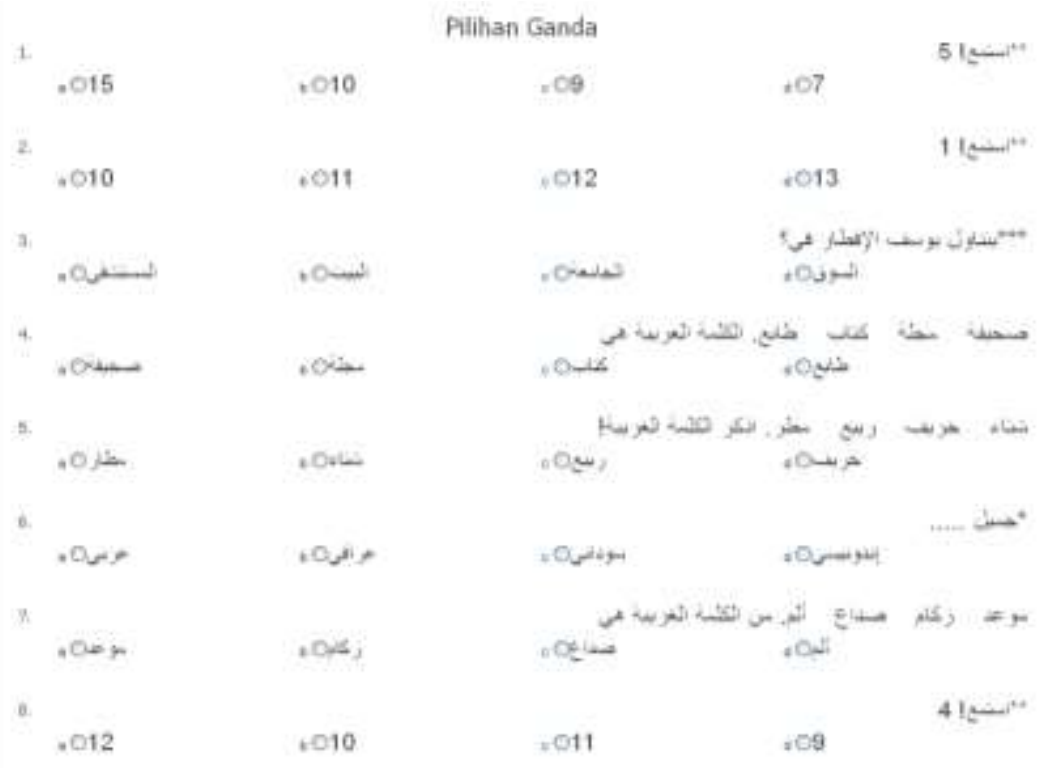

Gambar 4.17 butir soal pilihan ganda 
Arabi : Journal of Arabic Studies

Pilihan Benar-Salah

31.

OBenar

32.

OBenar

33.

OBenar

34.

OBenar

35. أصنَّي حَنْن صنَلاةٍ

OBenar

36.

OBenar

37.

OBenar

38.

OBenar

39.

OBenar
OSalah

OSalah

OSalah

OSalah

OSalah

OSalah

OSalah

OSalah

OSalah

$$
\text { با زينِب! في أثي جانعة نَدرس؟ }
$$

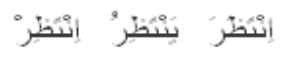

$$
\text { في الإسلان عبدأن }
$$$$
\text { لن أنت جاوي؟ }
$$

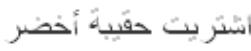

قرأت ألمجذة في ألغر فة

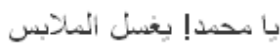

ألجانعة بعيدةً صن الثرَّة

Gambar 4.18 butir soal benar-salah

Pada menu ujian ini, selain butir soal pilihan ganda dan benar salah didesain juga waktu pengisian soal. Waktu yang disediakan mengerjakan soal adalah 2 jam. Jam tersebut berjalan mundur. Setelah semua soal dikerjakan oleh mahasiswa kemudian mereka harus mengklik "KIRIM" dan akan muncul menu hasil seperti yang tampak pada gambar di bawah ini:

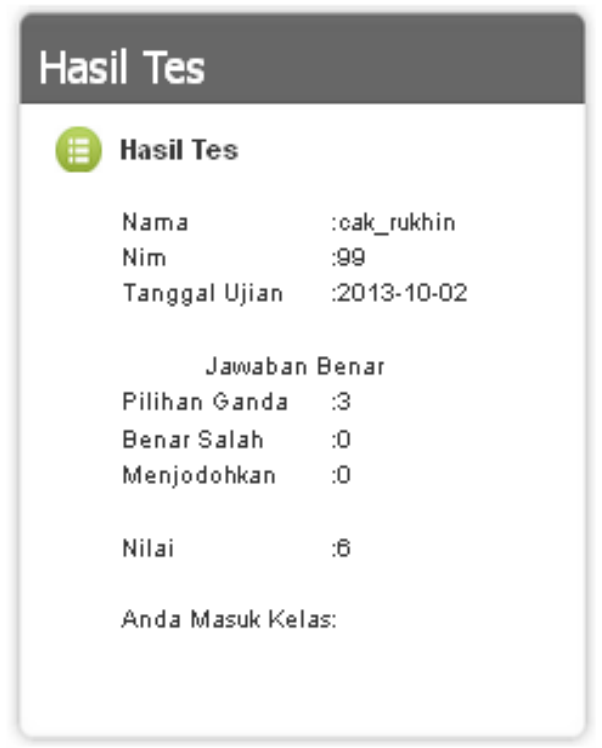

Gambar 4.19 hasil tes mahasiswa 
Berdasarkan hasil pelaksanaan ikhtibär tashnifi yang dilakukan oleh 90 mahasiswa baru jurusan Sastra Arab didapat data sebagai berikut:

\begin{tabular}{|c|c|c|c|c|c|c|}
\hline No & Nama & NIM & PG & BS & Nilai & Kelas \\
\hline 1. & Fitriatuzzuhro & 130231616438 & 29 & 20 & 98 & $\mathrm{~A}$ \\
\hline 2. & Nudya Kuntum Khoirel Abidah & 130231616408 & 27 & 20 & 94 & $\mathrm{~A}$ \\
\hline 3. & Bagus & 130231616425 & 29 & 17 & 92 & $\mathrm{~A}$ \\
\hline 4. & Badriatul Amalia Romadhon & 130231616407 & 28 & 18 & 92 & $\mathrm{~A}$ \\
\hline 5. & Darsa Muhammad & 130231601894 & 27 & 19 & 92 & $\mathrm{~A}$ \\
\hline 6. & Ichwanul Karim & 130231616442 & 27 & 19 & 92 & $\mathrm{~A}$ \\
\hline 7. & Ummy Sayyidah & 130231616412 & 28 & 17 & 90 & A \\
\hline 8. & Tria Agus Setianingsih & 130231616444 & 25 & 18 & 86 & $\mathrm{~A}$ \\
\hline 9. & Dwike Riski Amanah & 130231616419 & 23 & 20 & 86 & $\mathrm{~A}$ \\
\hline 10. & Muhammad Maqfurin & 130231616413 & 26 & 17 & 86 & $\mathrm{~A}$ \\
\hline 11. & Najmuddin & 130231601868 & 27 & 16 & 86 & $\mathrm{~A}$ \\
\hline 12. & Rudita Aulia Septiandini & 130231601856 & 24 & 18 & 84 & $\mathrm{~A}$ \\
\hline 13. & Luthvia Mualifatuz Zuhro' & 130231601876 & 27 & 15 & 84 & A \\
\hline 14. & Zahwa Isfarani & 130231601863 & 27 & 15 & 84 & $\mathrm{~A}$ \\
\hline 15. & Siti Malichah & 130231601881 & 25 & 17 & 84 & $\mathrm{~A}$ \\
\hline 16. & Wiwik Jumakyah & 130231616443 & 27 & 14 & 82 & $\mathrm{~A}$ \\
\hline 17. & Hikmatul Fauziah & 130231616420 & 25 & 16 & 82 & $\mathrm{~A}$ \\
\hline 18. & Hanna Fauzia & 130231601870 & 24 & 17 & 82 & $\mathrm{~A}$ \\
\hline 19. & Achmad Ivan Bahalwan & 130231601866 & 22 & 19 & 82 & $\mathrm{~A}$ \\
\hline 20. & Fachrur Rozi Alfarabi & 130231601860 & 28 & 13 & 82 & $\mathrm{~A}$ \\
\hline 21. & Intan Umi Salmah & 130231601867 & 26 & 15 & 82 & $\mathrm{~A}$ \\
\hline 22. & Yuyun Musyarofah & 130231616428 & 21 & 19 & 80 & $\mathrm{~A}$ \\
\hline 23. & Ria Adi Lestari Ningsih & 130231616415 & 21 & 19 & 80 & $\mathrm{~A}$ \\
\hline 24. & Khuzaimah & 130231601855 & 25 & 15 & 80 & $\mathrm{~A}$ \\
\hline 25. & Jihan Firdausy & 130231601859 & 26 & 14 & 80 & $\mathrm{~A}$ \\
\hline 26. & Ulya Kamalah & 130231616424 & 23 & 17 & 80 & $\mathrm{~A}$ \\
\hline 27. & Moh Ali & 130231616414 & 27 & 12 & 78 & $\mathrm{~A}$ \\
\hline 28. & Pundhi Raras Purbosari & 130231601889 & 19 & 20 & 78 & $\mathrm{~A}$ \\
\hline 29. & Ahmad Wildan Najib & 130231616421 & 24 & 15 & 78 & $\mathrm{~A}$ \\
\hline 30. & Nur Indah Fajarwati & 130231616435 & 26 & 13 & 78 & $\mathrm{~A}$ \\
\hline 31. & Ma'ruufatiy Mabruukah & 130231616411 & 22 & 10 & 76 & $\mathrm{~B}$ \\
\hline 32. & Azizah Rochmatu Laili & 130231616426 & 26 & 13 & 76 & $\mathrm{~B}$ \\
\hline 33. & Ahmad Fahrudin Azis & 130231616441 & 22 & 16 & 76 & $\mathrm{~B}$ \\
\hline 34. & Rizky Halimatus Sa'diyah & 130231616423 & 26 & 12 & 76 & $\mathrm{~B}$ \\
\hline 35. & Fitri Tarwiyati & 130231601874 & 26 & 11 & 74 & $\mathrm{~B}$ \\
\hline 36. & Muhammad Mukhlisin & 130231616434 & 25 & 12 & 74 & $\mathrm{~B}$ \\
\hline 37. & Hervina Uji Laksana & 130231616440 & 23 & 14 & 74 & $\mathrm{~B}$ \\
\hline 38. & Ilfa Nur Zuroidah & 130231616439 & 19 & 18 & 74 & $\mathrm{~B}$ \\
\hline 39. & Milladyna Nurfaiqoh & 130231616409 & 23 & 14 & 74 & $\mathrm{~B}$ \\
\hline 40. & Mahmudi & 130231616445 & 24 & 13 & 74 & $\mathrm{~B}$ \\
\hline 41. & Naila Himmatil Aliyah & 130231616418 & 23 & 14 & 74 & $\mathrm{~B}$ \\
\hline 42. & Siti Diyah Ayu Rohmatul K & 130231601862 & 23 & 14 & 74 & $\mathrm{~B}$ \\
\hline
\end{tabular}


Arabi : Journal of Arabic Studies

\begin{tabular}{|c|c|c|c|c|c|c|}
\hline No & Nama & NIM & PG & BS & Nilai & Kelas \\
\hline 43. & Diyana Kartikasari & 130231601883 & 24 & 12 & 72 & $\mathrm{~B}$ \\
\hline 44. & Intan Nisful Laila & 130231616451 & 23 & 13 & 72 & $\mathrm{~B}$ \\
\hline 45. & Ahsana Prayoga & 130231601873 & 22 & 14 & 72 & $\mathrm{~B}$ \\
\hline 46. & Lailatul Maghfiroh & 130231601875 & 24 & 12 & 72 & $\mathrm{~B}$ \\
\hline 47. & Assaadatui Hamidah & 130231601864 & 22 & 13 & 70 & $\mathrm{~B}$ \\
\hline 48. & Halimatus Sa'diyah & 130231616437 & 20 & 15 & 70 & $\mathrm{~B}$ \\
\hline 49. & Ana Mahbubah & 130231616429 & 20 & 14 & 68 & $\mathrm{~B}$ \\
\hline 50. & Asiefatul Fikriyyah & 130231616427 & 21 & 12 & 66 & $\mathrm{~B}$ \\
\hline 51. & Eka Nur Khamdanah & 130231616446 & 23 & 10 & 66 & $\mathrm{~B}$ \\
\hline 52. & Firdina Raudhotul Munauwaroh & 130231601879 & 18 & 14 & 64 & $\mathrm{~B}$ \\
\hline 53. & Hikmatul Ayu Nisa & 130231616422 & 24 & 7 & 62 & $\mathrm{~B}$ \\
\hline 54. & Dewi Puspita Sari & 130231601869 & 20 & 11 & 62 & $\mathrm{~B}$ \\
\hline 55. & Ainal Mardiyah & 130231616417 & 20 & 11 & 62 & $\mathrm{~B}$ \\
\hline 56. & Fausi Resa Pahlevi & 130231616431 & 18 & 13 & 62 & $\mathrm{~B}$ \\
\hline 57. & Firman Afrian Pratama & 130231601893 & 19 & 11 & 60 & $\mathrm{~B}$ \\
\hline 58. & Rijalul Ghifar Al Fanani & 130231601900 & 20 & 10 & 60 & $\mathrm{~B}$ \\
\hline 59. & Kharisma Bunga Ramadhan & 130231601884 & 19 & 11 & 60 & $\mathrm{~B}$ \\
\hline 60. & Lailaturrahmah Darti Arini & 130231601888 & 14 & 15 & 58 & $\mathrm{C}$ \\
\hline 61. & Herman & 130231601871 & 18 & 11 & 58 & $\mathrm{C}$ \\
\hline 62. & Nur Aini Choiriyah & 130231616436 & 21 & 8 & 58 & $\mathrm{C}$ \\
\hline 63. & Lia Faridatus Sha'diyah & 130231601896 & 19 & 10 & 58 & $\mathrm{C}$ \\
\hline 64. & Nur Hidayah & 130231601880 & 19 & 9 & 56 & $\mathrm{C}$ \\
\hline 65. & Maya Eka Armita Mu'asholi & 130231601892 & 19 & 9 & 56 & $\mathrm{C}$ \\
\hline 66. & Rian Tri Ahmadi & 130231616447 & 19 & 9 & 56 & $\mathrm{C}$ \\
\hline 67. & Istiqomah & 130231601898 & 19 & 9 & 56 & $\mathrm{C}$ \\
\hline 68. & Nurcahyani Arifin & 130231601899 & 19 & 9 & 56 & $\mathrm{C}$ \\
\hline 69. & Siti Mutmainah & 130231601858 & 19 & 9 & 56 & $\mathrm{C}$ \\
\hline 70. & Khafid & 130231601882 & 20 & 8 & 56 & $\mathrm{C}$ \\
\hline 71. & Akhmad Nurhidayah & 130231601872 & 20 & 7 & 54 & $\mathrm{C}$ \\
\hline 72. & Salim & 130231616405 & 19 & 7 & 52 & $\mathrm{C}$ \\
\hline 73. & Latifah & 130231601857 & 17 & 9 & 52 & $\mathrm{C}$ \\
\hline 74. & Diana Lin Hasanah & 130231616449 & 19 & 6 & 50 & $\mathrm{C}$ \\
\hline 75. & Vita Lely Ardiyanti & 130231601895 & 12 & 13 & 50 & $\mathrm{C}$ \\
\hline 76. & Ulul Azmi & 130231601885 & 12 & 13 & 50 & $\mathrm{C}$ \\
\hline 77. & Firza Anisa Maulina & 130231601865 & 13 & 10 & 46 & $\mathrm{C}$ \\
\hline 78. & Badriyah & 130231601887 & 14 & 9 & 46 & $\mathrm{C}$ \\
\hline 79. & Nurul Alfiah & 130231601891 & 13 & 10 & 46 & $\mathrm{C}$ \\
\hline 80. & Febri Arifatur Romdhani & 130231601897 & 13 & 10 & 46 & $\mathrm{C}$ \\
\hline 81. & Toherman & 130231616433 & 13 & 10 & 46 & $\mathrm{C}$ \\
\hline 82. & Syifa' Assegaf & 130231616410 & 13 & 10 & 46 & $\mathrm{C}$ \\
\hline 83. & Ahmad Izzuddin & 130231601877 & 13 & 10 & 46 & $\mathrm{C}$ \\
\hline 84. & Dwi Anggita & 130231616430 & 13 & 10 & 46 & $\mathrm{C}$ \\
\hline 85. & Luqmanul Yahya & 130231601861 & 13 & 10 & 46 & $\mathrm{C}$ \\
\hline 86. & Much Alfi Nazlil & 130231616450 & 11 & 9 & 40 & $\mathrm{C}$ \\
\hline
\end{tabular}


Arabi : Journal of Arabic Studies

\begin{tabular}{|l|l|c|r|r|r|c|}
\hline No & \multicolumn{1}{|c|}{ Nama } & NIM & PG & BS & Nilai & Kelas \\
\hline 87. & Habib Nur Ahmad & 130231601886 & 10 & 10 & 40 & C \\
\hline 88. & M. Husni Mubarok & 130231616416 & 17 & 0 & 34 & C \\
\hline 89. & Syafiq Abror Maromy & 130231616406 & 12 & 2 & 28 & C \\
\hline 90. & Nur Kholilah & 130231601890 & 12 & 3 & 28 & C \\
\hline
\end{tabular}

Berdasarkan tabel di atas, didapatkan data bahwa (1) 30 mahasiswa memperoleh nilai 78-94 menempati kelas A, (2) 30 mahasiswa memperoleh nilai 60-76 dan menempati kelas B, dan (3) 30 orang mahasiswa memperoleh nilai 24-58 menempati kelas $\mathrm{C}$.

\section{Pembahasan}

1. Langkah-langkah desain aplikasi ikhtibar tashnifi (tes penempatan) berbasis web untuk mahasiswa Jurusan Sastra Arab Fakultas Sastra Universitas Negeri Malang

Sebagaimana yang telah disebutkan di hasil penelitian, bahwa sebelum peneliti membuat rancangan ikhtibär tashnifi berbasis web, hal pertama yang peneliti lakukan adalah observasi dan melakukan kajian pustaka. Observasi dilakukan sejak tahun 2011, ketika peneliti menjadi salah satu tim pelaksanaan ikhtibär tashniffi untuk mahasiswa baru. Menurut peneliti, ikhtibar tashnifi yang selama ini berjalan bersifat manual dan banyaknya waktu terbuang untuk mengevaluasi dan menghitung hasil tes. Seiring dengan perkembangan zaman, muncullah berbagai macam program tes berbasis web atau berbantuan komputer.

Berkaitan dengan kajian pustaka yang peneliti lakukan adalah dengan membaca beberapa hasil penelitian tentang tes berbasis komputer. Salah satu hasil penelitian yang peneliti kaji adalah penelitian yang berjudul pengembangan sistem test penempatan (placement test) berbasis komputer yang dilakukan oleh Palelleng (2007). Hasil penelitiannya adalah sebuah sistem yang siap diimplementasikan di LIA Yogyakarta untuk pelaksanaan test penempatan berbasis komputer. Sistem ini dapat memberi keuntungan bagi penggunanya baik dari segi kemudahan penggunaan sistem, kualitas informasi dan manfaat informasi yang dihasilkan sistem. Dari hasil observasi dan kajian pustaka tersebut, akhirnya peneliti mengembangkan ikhtibar tashnifi berbasis web.

Proses selanjutnya adalah peneliti mendesain ikhtibar tashnifi berbasis web. Program yang digunakan untuk mendesain ikhtibar adalah adobe dreamweaver CS6 dengan ekstensi php karena program ini tidak terlalu besar ukurannya sehingga tidak menjadi berat ketika diupload ke internet. Sebelum menjalankan program ikhtibar terlebih dahulu harus diinstal server local dan membuat database.

Tujuan dari server lokal (offline) adalah menggantikan server ke internet (online). Menurut Rohman (2010) bahwa tujuan dari server lokal adalah pengganti dari koneksi internet dan beberapa software yang bisa dijadikan server lokal antara lain wamp server, xampp, dan lamp. Keuntungan dari server lokal adalah (a) tidak memerlukan koneksi internet, (b) loading page cepat; loading page akan terasa lebih cepat di bandingkan dengan yang online, karena file-file yang di load memang ada dalam komputer, dan (c) sarana testing.

Banyak program/software yang digunakan untuk membuat tes secara umum berbasis web diantaranya moddle, Atutor, Tcexam, dan claroline. Akan tetapi peneliti memilih mendesain sendiri program ikhtibar tersebut. Hal ini sesuai dengan apa yang disampaikan oleh Yusuf (2013) bahwa PHP adalah script yang menyatu dengan HTML dan ada diserver. Bahasa ini bisa mengubah halaman halaman web yang jauh lebih dinamis. Tujuan utama pada PHP yaitu agar seorang perancang web dapat menulis halaman web yang jauh lebih dinamik dengan cepat. Program ini termasuk pemrograman yang berbasis web yang mudah di pahami dari pada bahasa pemrograman yang lain. Tetapi PHP tidak bisa di akses secara langsung tanpa adanya web server.

Dari segi desain tampilan, sudah ditambahkan fitur-fitur yang menarik sehingga mahasiswa dapat menikmati media ini. Hal ini sesuai yang disampaikan oleh Dwiastuti (2010) bahwa kelebihan ujian online adalah (a) ujian online merupakan ujian yang menyenangkan tetapi agak menegangkan karena kita harus tetap mereload page utama untuk mengetahui apakah soal ujian

Vol. 1 No. 2 | 46-49

Copyright @ 2016 | ARABI | p-ISSN 2548-6616 | e-ISSN 2548-6624 
yang berikutnya telah keluar, (b) mengurangi global warming, karena kita tidak harus ujian menggunakan kertas, (c) mahasiswa aktif untuk mereload, mencari tau apakah soal ujian berikutnya sudah diposting, (d) feedback berupa komentar yang diberikan dapat membantu mahasiswa untuk lebih semangat.

Berkaitan dengan hasil analisis data tetang kevalidan dan kelayakan aplikasi ikhtibar tashnifi dapat diketahui bahwa kalayakan atau kevalidan materi ikhtibar adalah $81,25 \% \%$ dengan rekomendasi valid. Sedangkan hasil analisis dari ahli media didapatkan nilai adalah 85\%. Rekomendasi yang diberikan oleh ahli materi adalah valid. Berdasarkan hasil tersebut dapat ditarik kesimpulan bahwa aplikasi ini layak diujikan kepada mahasiswa.

\section{Mendeskripsikan penggunaan aplikasi ikhtibar tashnifi (tes penempatan) berbasis web untuk mahasiswa Jurusan Sastra Arab Fakultas Sastra Universitas Negeri Malang}

Sebelum melakukan ikhtibar online, mahasiswa diharuskan mendaftar terlebih dahulu. Ini sesuai dengan karakteristik tes online bahwa sebelum melakukan pembelajaran harus login terdahulu agar data mahasiswa atau peserta didik terrekam baik dari berapa kali mereka mengunjungi web dan total skor nilai yang didapat.

Mahasiswa melakukan ikhtibar setelah login dan dalam program tersebut ada panduan tes online yang harus dibaca mahasiswa dan memahaminya. Ini sesuai dengan yang disampaikan Wahzudik (2010) bahwa salah satu karakteristik pembelajaran melalui internet (online) adalah informasi bahan ajar menarik perhatian. Maksudnya adalah informasi bahan penarik perhatian yang terdapat dalam pembelajaran internet harus memperhatikan (a) penggunaan gambar yang berwarna-warni, (b) memunculkan animasi, (c) penggunaan nada atau lagu, dan (d) komposisi tampilan yang proporsional (huruf atau gambar tidak terlalu kecil).

Setelah memahami panduan tes, mahasiswa melakukan tes sendiri dengan mengerjakan latihan yang sudah disiapkan. Sebagaimana karakteristik pembelajaran melalui komputer bahwa evaluasi dapat dilaksanakan secara terbuka yaitu dapat dilakukan di mana pun internet dapat diakses. Akan tetapi karena ini digunakan untuk menentukan kelas, maka pelaksanaannya dilakukan serempak untuk menghindari contekan. Selain itu juga dapat dilaksanakan secara tertutup, dengan pengertian hanya dilakukan di suatu lokasi tertentu untuk menghindari kemungkinan yang mengerjakan adalah orang lain (Wahzudik, 2010).

Tes yang ditampilkan dalam aplikasi ini berupa tes interkatif dengan mengklik jawaban yang benar. Ada dua bentuk tes yang ditampilkan yaitu pilihan ganda dan benar-salah. Kalau diperhatikan kedua bentuk tes itu adalah berupa tes objektif. Pemilihan tes objektif dalam tes online memiliki kelebihan yaitu (a) lebih respektif mewakili isi dan luas bahan, lebih objektif, dapat di hindari campur tangannya unsur-unsur subjektif baik dari segi peserta didik maupun segi pengajar yang memeriksa, (b) lebih mudah dan cepat cara memeriksanya karena dapat menggunakan kunci tes bahkan alat-alat hasil kemajuan teknologi, (c) pemeriksaanya dapat diserahkan orang lain, (d) dalam pemeriksaan tidak ada unsur subjektif yang mempengaruhi, (e) untuk menjawab test objektif tidak banyak memakai waktu, (f) reabilitasnya lebih tinggi kalau di bandingkan dengan tes Essay, karena penilainnya bersifat objektif, (g) Validitas tes objektif lebih tinggi dari tes essay, karena samplingnya lebih luas, (h) pemberian nilai dan cara menilai test objektif lebih cepat dan mudah karena tidak menuntut keahlian khusus dari pada si pemberi nilai (Sukmadinata, 2005:187).

Dalam menjawab tes interaktif, mahasiswa mendapat satu kali kesempatan menjawab pernyataan. Tujuan dari program ini adalah agar mahasiswa dengan cermat dan teliti membaca pernyataan dengan baik sebelum menjawab. Inilah salah satu kelemahan tes benar-salah bahwa karena alternatif jawabannya hanya dua yakni benar atau salah, maka kemungkinan jawaban yang bersifat spekulasi akan terjadi (Ainin dkk, 2006:123).

Aplikasi ikhtibar tashnifi ini juga dilengkapi dengan waktu mengerjakan. Penentuan waktu dalam tes benar-salah ini bertujuan untuk memberikan kesempatan kepada mahasiswa 


\section{Arabi : Journal of Arabic Studies}

memanfaatkan waktu semaksimal mungkin. Penentuan waktu ini sesuai yang disampaikan oleh Ainin (2006:95) bahwa perihal yang harus dipertimbangkan dalam menentukan jumlah butir tes adalah alokasi waktu yang tersedia untuk penyelenggaraan tes. Untuk menentukan berapa jumlah butir tes yang harus disusun sesuai dengan waktu yang tersedia memang tidak ada batasan yang pasti.

Berkaitan dengan hasil yang diperoleh mahasiswa bermacam-macam. Ada beberapa faktor yang mempengaruhi di antaranya (1) latar belakang pendidikan mahasiswa, (2) psikologi mahasiswa ketika mengerjakan soal, (3) kondisi ruang ujian.

\section{Simpulan} berikut:

Berdasarkan hasil peneltian dan pembahasan di atas, maka dapat disimpulkan hal-hal sebagai

1. Untuk merancang aplikasi ikhtibār tashnifi berbasis web untuk mahasiswa baru Jurusan Sastra Arab Fakultas Sastra Universitas Negeri Malang hal pertama yang perlu diperhatikan adalah observasi, mengkaji vahan pustaka dan mendesain program ikhtibar. Sebelum menggunakan program ikhtibär terlebih dahulu harus diinstal server lokal, membuat database dan menjalankan program. Berkaitan dengan hasil analisis data tetang kevalidan dan kelayakan aplikasi ikhtibär tashnifi dapat diketahui bahwa kalayakan atau kevalidan materi ikhtibar adalah $81,25 \%$ dengan rekomendasi valid. Sedangkan hasil analisis dari ahli media didapatkan nilai adalah $85 \%$. Rekomendasi yang diberikan oleh ahli materi adalah valid.

2. Untuk melakukan ikhtibăr, mahasiswa harus mengisi form pendaftaran agar data mahasiswa atau peserta didik terrekam dan melakukan ujian dengan menjawab semua soal. Bentuk tes yang ditampilkan adalah berupa tes objektif. []

\section{Daftar Rujukan}

Ahsanuddin, Mohammad dkk. 2010. Pengembangan Perangkat Lunak Berbasis Hot Potatoes Sebagai Model Tes Interaktif dalam Matakuliah Qiro'ah I (Membaca) Mahasiswa Jurusan Sastra Arab Fakultas Sastra Universitas Negeri Malang. Hasil penelitian tidak dipublikasikan. Malang: Fakultas Sastra Universitas Negeri Malang.

Ainin, Moh. 2006. Evaluasi dalam Pembelajaran Bahasa Arab. Malang: Misykat.

Arikunto, Suharsimi. 2006. Prosedur Penelitian: Suatu Pendekatan Praktik. Jakarta: PT. Rineka Cipta.

al-Jabal, Riyadh Arif. 2009. Al-Wasail al-Ta’limiyyah wa Tharā'iq al-Tadris. Suriyah: Dar AlAsma'.

Hafid, Dedi Herdiana. 2013. Keunggulan dan Kelemahan Tes Objektif. http://file.upi.edu/Direktori/FIP/JUR._PSIKOLOGI_PEND_DAN_BIMBINGAN/195903271 986011-DEDI_HERDIANA_HAFID/KEUNGGULAN_DAN_KELEMAHAN_TES_ OBJEKTIF_\%5BCompatibility_Mode\%5D.pdf

Djalal, M. Fachruddin. 1985. Penilaian Dalam Pengajaran Bahasa Asing/Arab. Malang: IKIP Malang.

Djiwandono, Soenardi. 2011. Tes Bahasa Pegangan bagi Pengajar Bahasa. Jakarta: PT. Indeks.

Dwiastuti, Winda. 2010. Kekurangan dan Kelebihan Ujian Online dengan Ujian Konvensional. http://08025windadwiastuti.blogspot.com/2010/12/kekurangan-dan-kelebihan-ujianonline.html

Palelleng, Srivan. 2007. Pengembangan Sistem Test Penempatan (Placement Test) Berbasis Komputer. Tesis tidak diterbitkan. Yogyakarta: UGM. 
Arabi : Journal of Arabic Studies

Sugiyono. 2008. Metode Penelitian Pendidikan Pendekatan Kuantitatif, Kualitatitf dan R\&D. Bandung: Penerbit AlfaBeta.

Sukmadinata, Nana Syaodih. 2005. Pengembangan Kurikulum: Teori dan Praktek. PT Remaja Rosdakarya: Bandung.

Wahzudik, Niam. 2010. Menuju Pembelajaran Online (E-learning). (Online), (http://niamw.files.wordpress.com/2010/04/e-learning.pdf), diakses 3 Oktober 2012

Yusuf. 2013. Kekurangan dan Kelebihan PHP. http://www.jejaring.web.id/kekurangan-dankelebihan-php/ online diakses pada tanggal 8 Oktober 2013. 